\title{
A conserved histone deacetylase with a role in the regulation of cytokinesis in Schizosaccharomyces pombe
}

\author{
Charnpal Grewal, Jack Hickmott, Stefan Rentas and Jim Karagiannis*
}

\begin{abstract}
Background: In Schizosaccharomyces pombe the SET domain protein, Set3p - together with its interacting partners, Snt1p, and Hif2p - form a complex that aids in preventing cell division failure upon mild cytokinetic stress. Intriguingly, the human orthologs of these proteins (MLL5, NCOR2, and TBL1X) are also important for the faithful completion of cytokinesis in tissue culture cells. Since MLL5, NCOR2, and TBL1X form a complex with the histone deacetylase, HDAC3, we sought to determine if an orthologous counterpart played a regulatory role in fission yeast cytokinesis.

Results: In this report we identify the hos2 gene as the fission yeast HDAC3 ortholog. We show that Hos $2 p$ physically interacts with Set3p, Snt1p, and Hif2p, and that hos $2 \Delta$ mutants are indeed compromised in their ability to reliably complete cell division in the presence of mild cytokinetic stresses. Furthermore, we demonstrate that overexpression of hos2 causes severe morphological and cytokinetic defects. Lastly, through recombinase mediated cassette exchange, we show that expression of human HDAC3 complements the cytokinetic defects exhibited by hos $2 \triangle$ cells.

Conclusions: These data support a model in which Hos $2 p$ functions as an essential component of the Set3pSnt1p-Hif2p complex with respect to the regulation of cytokinesis. The ability of human HDAC3 to complement the cytokinesis defects associated with the deletion of the hos2 gene suggests that further analysis of this system could provide insight into the role of HDAC3 in both the regulation of cell division, as well as other biological processes influenced by HDAC3 deacetylation.
\end{abstract}

Keywords: Fission yeast, Cytokinesis, Cell division, Histone deacetylase

\section{Background}

In the fission yeast, Schizosaccharomyces pombe, regulatory mechanisms exist to ensure that cytokinesis takes place at the correct spatial location within the cell and at the proper temporal position of the cell cycle [1-5]. The proper spatial positioning of the cytokinetic actomyosin ring is controlled by the anilin-related protein, Mid1p, which - upon entry into mitosis - re-localizes from the nucleus to a medial band defining the future site of cell division [5-9]. The initiation of ring constriction, on the other hand, is signalled by a conserved regulatory module referred to as the Septation Initiation Network (SIN). The SIN is composed of a

\footnotetext{
*Correspondence: jkaragia@uwo.ca

Department of Biology, University of Western Ontario, London, Ontario N6A-5B7, Canada
}

GTPase signalling cascade that is essential for the temporal co-ordination of cytokinesis, ring constriction, and for the deposition of the division septum $[3,5,9,10]$.

In addition to these mechanisms, recent work has also supported the existence of a cytokinesis monitoring system. This system has the capacity to generate a prolonged cytokinesis competent state (characterized by delayed entry into mitosis and the continuous repair/reestablishment of the actomyosin ring) that allows for the successful completion of cell division upon mild cytokinetic stresses [11-17]. The key components of this regulatory module are the Cdc14 family phosphatase, Clp1p, and the 14-3-3 protein, Rad24p. When challenged by stresses that perturb the cell division machinery, a phosphorylated form of Clp1p (normally nucleolar) becomes bound by Rad24p leading to its prolonged retention in

\section{Biomed Central}


the cytoplasm and the extended activation of the SIN. In the absence of either Clp1p or Rad24p, cells are unable to maintain SIN signalling leading to cytokinesis failure and the generation of inviable, multinucleate cells $[13,15,18]$.

A useful strategy in both identifying these regulators, and in defining their roles, has involved the treatment of fission yeast cells with the actin depolymerising drug, Latrunculin A (LatA) [11-15]. At the concentrations used (20-50 times less than that needed to completely depolymerize the actin cytoskeleton) such treatment impedes constriction of the actomyosin ring and is lethal to both $\operatorname{clp} 1 \Delta$ and rad24 $\Delta$ mutants (due to their inability to prolong the cytokinesis competent state). Wild-type cells in contrast, are able to complete cell division under these conditions, albeit at rates slower than in untreated cells.

Interestingly, a recent genome-wide genetic screen based on the isolation of deletion mutants hyper-sensitive to LatA, identified set3, hif2, and snt1 and showed that their respective gene-products form a nuclear-localized complex required for the dependable execution of cytokinesis. Further analysis demonstrated that set $3 \Delta$ mutants were unable to properly modulate the expression of stress response genes, suggesting a role for the Set3p complex in effecting changes in gene expression required to counter the effects of LatA induced stress [19].

Intriguingly, the set3, snt1, and hif2 genes are orthologous to human MLL5, NCOR2 and TBL1X, which together encode components of a histone deacetylase complex. Remarkably, knockdown of either of these genes in human HeLa cells results in increased rates of cytokinesis failure [20]. Since NCOR2, and TBL1X physically associate with the type I histone de-acetylase, HDAC3 - a highly conserved histone deacetylase with orthologs from Dictyostelium to multicellular mammals - we sought to determine if an orthologous counterpart played a regulatory role in fission yeast cytokinesis [20-22].

Here we identify the hos 2 gene as the fission yeast $H D A C 3$ ortholog. Hos2p, also known as Hda1p, is a nonessential histone de-acetylase known to affect H4K16 acetylation (primarily in the $5^{\prime}$ end of genes) as well as gene silencing and sporulation efficiency [23-25]. In this report we show that Hos $2 p$ exists in a complex with Set3p, Snt1p, and Hif2p, and that hos $2 \Delta$ mutants are also compromised in their ability to complete cytokinesis in the presence of low doses of LatA. Furthermore, a role in the regulation of cell division is supported by the severe morphological and cytokinetic defects observed upon hos 2 over-expression.

Lastly, we provide strong support for the conservation of HDAC3 function by demonstrating the ability of human $H D A C 3$ to complement the cytokinetic defects exhibited by hos $2 \Delta$ cells.

\section{Results}

Hos $2 p$ is required for the successful completion of cytokinesis in response to perturbation of the cell division machinery

[20-22] To determine if an ortholog of HDAC3 existed in $S$. pombe, and if it too played a role in the regulation of cytokinesis, A BLAST search using human HDAC3 as query was performed. This analysis revealed strong conservation of amino acid sequence between HDAC3 and fission yeast Hos2p (not be confused with the DASH complex subunit, Dad2p, which is also sometimes referred to using the gene name, hos 2 ). The proteins share $51 \%$ identity (63\% similarity), are of similar length (427 and 437 aa, respectively), and possess a single histone deacetylase domain (PFAM00850) that comprises almost the entire length of the protein (Additional File 1).

To determine if Hos2p played a role in cytokinesis, the hos 2 gene deletion mutant was purchased from the commercial supplier, Bioneer. After confirmation of the deletion via colony PCR, wild-type and hos $2 \Delta$ strains were grown to mid-log phase and serial dilutions plated onto YES media containing either $0.5 \mu \mathrm{M}$ LatA or DMSO (solvent control).

Interestingly, the hos $2 \Delta$ strain demonstrated a substantial decrease in viability when grown in the presence of LatA. In contrast, while the rate of growth of wild-type cells decreased in LatA media, viability was not affected (note the formation of small colonies even at the lowest dilution) (Figure 1A).

To determine if the sensitivity to LatA was related to defects in cytokinesis, both wild-type and hos $2 \Delta$ strains were grown in liquid YES media and then treated with either $0.5 \mu \mathrm{M}$ LatA or DMSO for 5 hours at $30^{\circ} \mathrm{C}$. Cells were then fixed and stained with DAPI and analine blue to visualize nuclei and cell wall/septal material, respectively. No obvious morphological or cytokinesis phenotypes were observed in hos $2 \Delta$ cells under normal growth conditions. However, in LatA media, hos $2 \Delta$ mutants were severely impaired in their ability to complete cell division and accumulated a large proportion of tetra-nucleate cells with fragmented septa. In contrast, the majority of wild-type cells were bi-nucleate and formed functional, albeit thickened and sometimes malformed septa (Figure 1B).

To quantitate the data, cells were classified into four different phenotypic categories:i) uni-nucleate cells, ii) bi-nucleate cells with a functional septum (i.e. the septum completely bisects the cell), iii) binucleate cells with a fragmented septum (i.e. the septum is non- functional and does not completely bisect the cell), and iv) tetra-nucleate cells. This analysis revealed that while over $40 \%$ of hos $2 \Delta$ cells were tetra-nucleate, only $6 \%$ of wild-type cells 


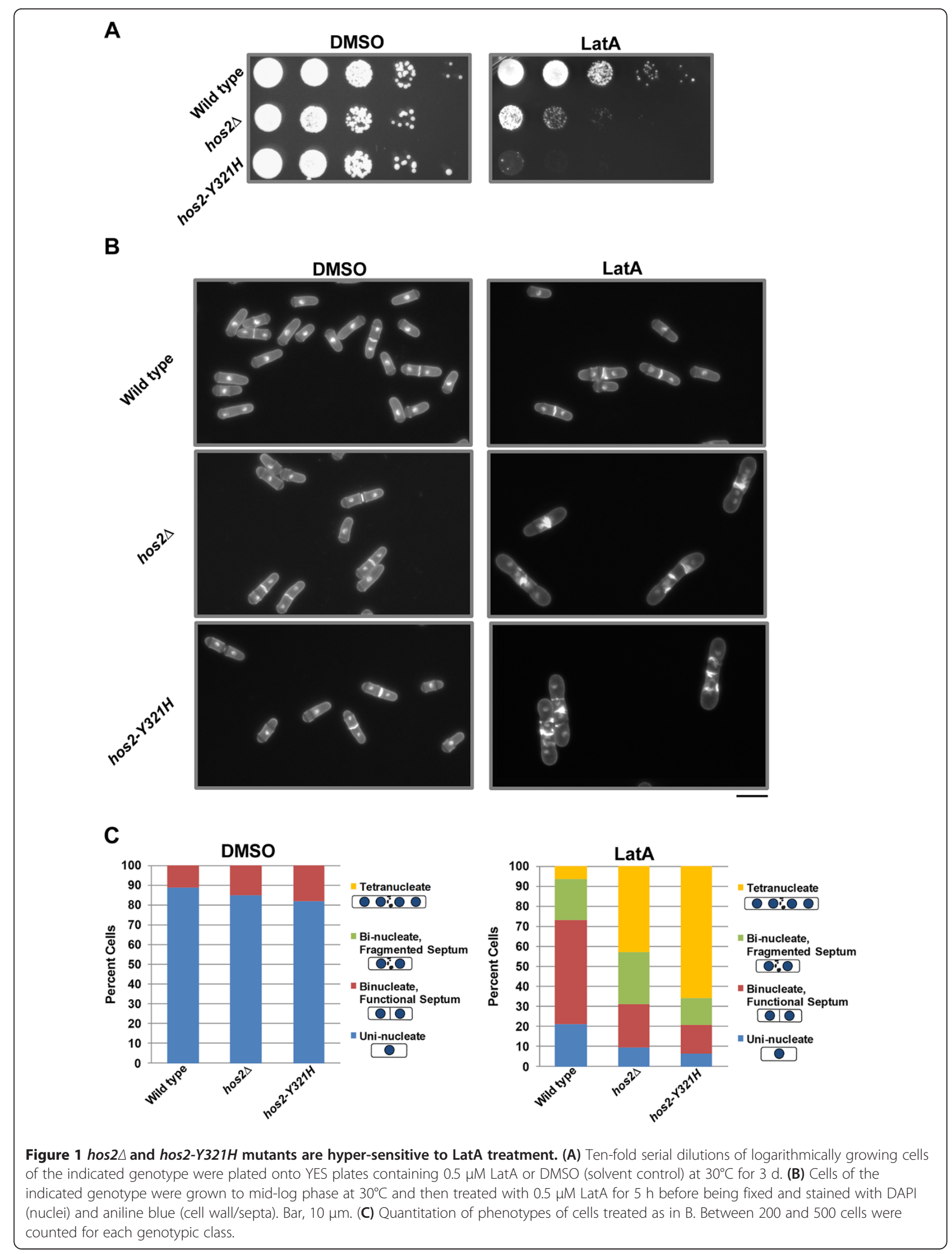


showed a similar phenotype. Moreover, while $72 \%$ of wild-type cells were either mono- nucleate, or bi-nucleate (with a functional septum), only $31 \%$ of hos $2 \Delta$ cells were similarly distributed (Figure $1 \mathrm{C}$ ). The phenotypes observed in hos $2 \Delta$ mutants upon LatA treatment are unlikely to be due to defects in SIN activity since two independent markers of active SIN signalling - Cdc7p localization to a single SPB, and increased export of Clp1p from the nucleolus to the cytoplasm [15] - were normal in hos $2 \Delta$ mutants upon exposure to LatA (Additional File 2).

An important role for Hos $2 p$ in responding to LatA treatment was also supported by synthetic genetic interactions between the hos $2 \Delta$ and $\operatorname{clp} 1 \Delta$ mutations. Since Clp1p is required for the function of the cytokinesis checkpoint, weak cytokinesis mutants often display stronger phenotypes in clp1 $\Delta$ backgrounds [15]. To test if this were true in the case of hos $2 \Delta$ mutants, clp $1 \Delta$, hos $2 \Delta$ and $\operatorname{clp} 1 \Delta$ hos $2 \Delta$ mutants were examined after treatment with both $0.1 \mu \mathrm{M}$ and $0.5 \mu \mathrm{M}$ LatA. Interestingly, while hos $2 \Delta$ and $\operatorname{clp} 1 \Delta$ single mutants were viable at $0.1 \mu \mathrm{M}$ LatA, double mutants displayed severe cytokinesis defects at this concentration (Additional File 3).

Lastly, we also noted that the presence of the hos $2 \Delta$ mutation was capable of lowering the restrictive temperature of the ts $c d c 15-140$ mutation by $\sim 2^{\circ} \mathrm{C}$ ( $c d c 15$ encodes an F-BAR protein required for contractile ring assembly; [26]) (Additional File 4). Interestingly, this decrease in the restrictive temperature of the $c d c 15-140$ mutation is similar to that caused by the presence of the $\operatorname{set} 3 \Delta, \operatorname{sit} 1 \Delta$, and hif2 $\Delta$ gene deletions in $c d c 15-140$ backgrounds. These data further support a common function for the hos2, set3, snt1, and hif2 genes [19].

Once having established that the Hos $2 \mathrm{p}$ protein was indeed involved in the regulation of cytokinesis, we explored the possibility that the protein's deacetylase activity was related to its function. To this end we created a mutant strain expressing a form of Hos $2 p$ in which the catalytically active tyrosine residue in the catalytic pocket was replaced with a catalytically inactive histidine residue $(\mathrm{Y} 321 \mathrm{H})$. Interestingly, the cytokinesis phenotypes of this mutant were more severe than those displayed by hos $2 \Delta$ cells. Cells bearing the $\mathrm{Y} 321 \mathrm{H}$ mutation were almost completely inviable in the presence of LatA and furthermore, over $60 \%$ were tetra-nucleate after 5 hours growth in liquid media containing $0.5 \mu \mathrm{M}$ LatA (Figure 1A-C).

To more closely examine the effects of LatA on cytokinesis we created a hos $2 \Delta$ strain expressing a marker of the actomyosin ring, Rlc1-GFP [27]. Using the CellAsics ONIX Microfluidic Perfusion Platform, we were able to monitor the constriction of the actomyosin ring while perfusing liquid YES media containing either $0.5 \mu \mathrm{M}$ LatA or DMSO as a solvent control. In DMSO media, wild-type cells were able to fully constrict the ring in approximately $\sim 25$ minutes. Similarly, rings in hos $2 \Delta$ mutants grown in DMSO media displayed comparable kinetics and were also able to fully constrict in $\sim 25 \mathrm{~min}$ utes (Figure 2, top two rows; Additional Files 5 and 6). However, when grown in LatA media, hos $2 \Delta$ cells displayed dramatic differences in phenotype compared to wild type. The majority of wild-type cells were able to form and constrict the ring in the presence of LatA, albeit over a much longer time frame ( $~ 90$ minutes) than DMSO controls (7 out of 9 cells). The remainder (2 out of 9 cells) were able to maintain the integrity of the ring over this time frame, but were not able to fully constrict the ring over the 90 minute time-lapse. In contrast, hos $2 \Delta$ cells could not preserve the physical integrity of the ring. In LatA treated hos $2 \Delta$ mutants, Rlc1- GFP signal did not constrict and instead appeared to fragment ( 8 out of 8 cells) within 10-15 minutes (Figure 2, bottom two rows; Additional Files 7 and 8 ).

\section{Over-expression of Hos $2 \mathrm{p}$ results in severe morphological and/or cytokinetic defects}

To explore whether Hos2p played a dosage dependent role in cytokinesis we decided to test the effects of hos 2 over-expression using the pREP series of thiamine repressible expression vectors [28,29]. To this end, full length hos 2 was cloned downstream of the $n m t 1 / 41 / 81$ promoters present within the pREP1/41/81 plasmids and the constructs were transformed into wild-type strain, JK484 (Table 1). Full strength expression is obtained from the $n m t 1$ promoter, while $n m t 41$ and $n m t 81$ promoters contain site mutations that decrease expression to intermediate and low levels, respectively [28].

In the presence of thiamine (repressed) cells expressing hos 2 from either $n m t 41$, or $n m t 81$ promoters (as well as an empty vector control) displayed normal growth whereas cells expressing hos 2 from the nmt1 promoter showed slight growth inhibition (most likely due to the fact that expression from $n m t 1$ is somewhat "leaky") [28,29]. On the other hand, when grown in the absence of thiamine (de-repressed) cells expressing hos 2 displayed an inhibition of growth ranging from severe (in the case of the $n m t 1$ promoter) to intermediate (in the case of the $n m t 41$ promoter) to mild (in the case of the $n m t 81$ promoter) (Figure $3 \mathrm{~A}, \mathrm{~B}$ ).

Interestingly, expression of hos 2 from the nmt 1 promoter also led to a series of unusual and pleiotropic phenotypes related to morphogenesis and/or cytokinesis. While the majority of cells appeared normal, others displayed phenotypes ranging from i) slight morphological abnormalities such as a rounded, de-polarized appearance, ii) misplaced, but otherwise normal septa, iii) 


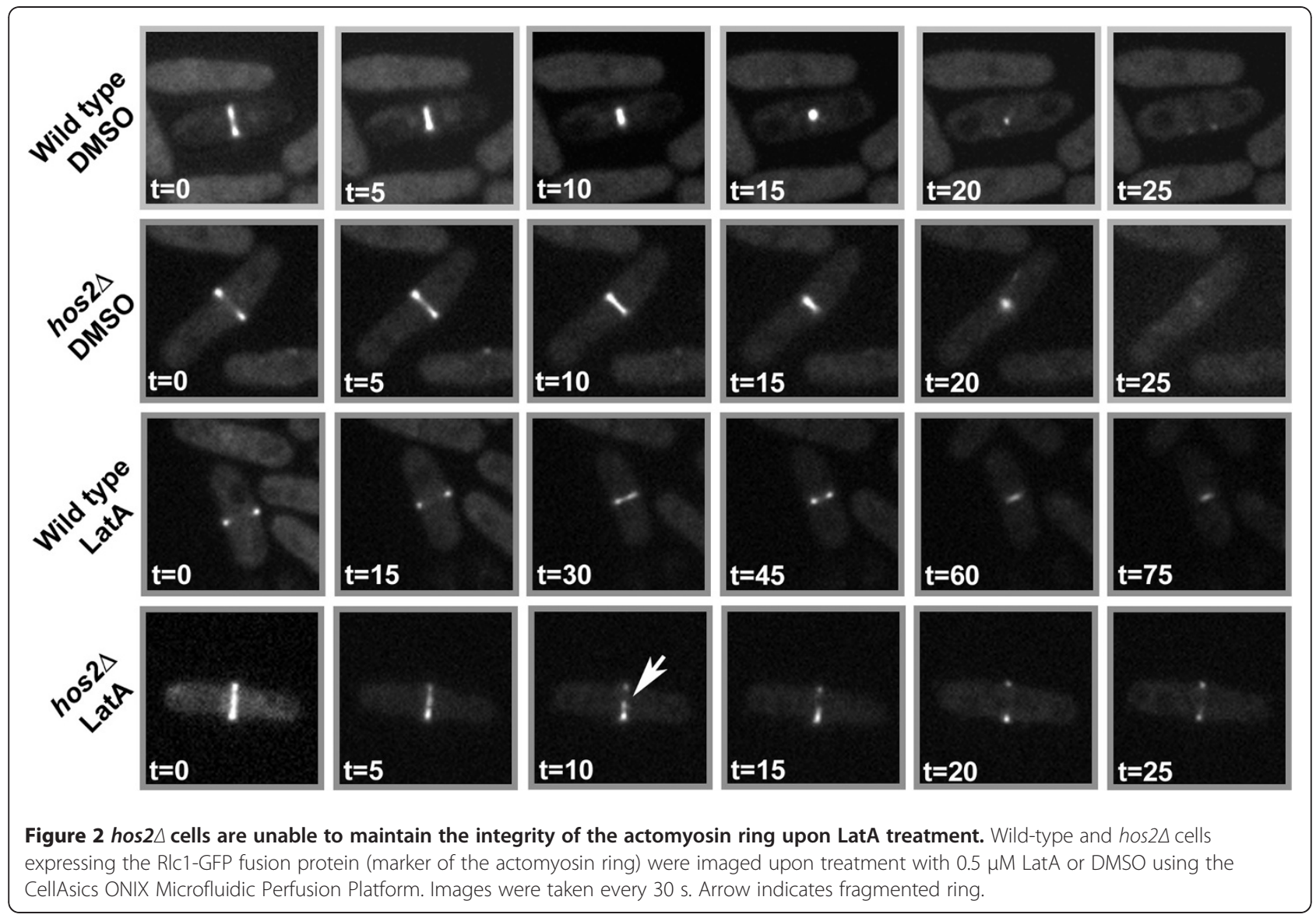

abnormally excessive and mis-localized septal deposition, iv) multiple septa v) highly elongated cells containing multiple aberrant deposits of septal material and vi) highly unusual branched and elongated cells (Figure 3C; Table 2). This broad range of phenotypes further supports a model where Hos2p plays a role in the regulation of cytokinesis and/or morphogenesis.

Hos $2 p$ is nucleo-cytoplasmic and physically interacts with Set3p, Snt1p, and Hif2p

We have previously shown that the Set3p, Snt1p, and Hif2p form a nuclear-localized complex. If indeed a member of this complex, Hos2p would be expected to localize (at least in part) to the nucleus. To test this prediction we created a strain expressing a C- terminal Hos2-GFP fusion protein under control of the native hos 2 promoter. Hos $2 p$ localized to both the cytoplasm and to the nucleus as judged by costaining with the nuclear dye, DAPI (Figure 4A). Furthermore, we determined that the intracellular distribution of Hos2p was not affected by LatA treatment (data not shown), nor did its localization change as a function of cell cycle position (Figure 4A). The localization of the Scw1p protein (enriched in the cytoplasm relative to the nucleus) was used as a control to ensure the validity of the observed nuclear signal (Figure 4A, bottom panels) [30].

To determine if Hos $2 \mathrm{p}$ was able to physically interact with members of the Set3p complex, in-vivo co-immunoprecipitation experiments using Myc or HA epitope tagged alleles were performed. Significantly, Hos2-Myc fusion proteins could be detected in anti- HA immunoprecipitates of Snt1-HA Hos2-Myc, Hif2-HA Hos2-Myc, and Set3-HA Hos2- Myc extracts, but not in extracts expressing only Hos2-Myc (Figure 4B). These results are consistent with high throughput proteomics experiments aimed at defining fission yeast protein complexes related to histone modification [31]. Taken together, these data suggest that Hos $2 p$ molecules can indeed exists within a complex with Snt1p, Hif2p, and/or Set3p.

\section{Expression of human HDAC3 complements the} cytokinesis defects associated with the hos 2 gene deletion

To further explore the possibility of functional conservation between human HDAC3 and fission yeast Hos2p, we utilized the technique of recombinase mediated cassette exchange to replace the endogenous Hos $2 p$ open 
Table 1 Strains used in this study

\begin{tabular}{|c|c|c|}
\hline Strain Name & Relevant Genotype & Source \\
\hline$\overline{J K 9}$ & clp1::ura4 $4^{+}$ura4-D18 $\mathrm{h}^{-}$ & JK Collection \\
\hline JK468 & hos2::KanMX4 ura4-D18 leu-32 ade6-216 & Bioneer \\
\hline$J K 484$ & ura4-D18 leu-32 ade6-216 his3-D1 & JK Collection \\
\hline$J K 561$ & $\begin{array}{l}\text { hos2-GFP::ura4+ ura4-D18 leu1-32 ade6- } \\
210 \text { his3-D1 }\end{array}$ & This Study \\
\hline JK648 & hos2-Y321H:::ura4 ${ }^{+}$ura4-D18 & This Study \\
\hline JK659 & rlc1GFP::ura4+ hos2::kanMX4 ura4-D18 & This Study \\
\hline JK737 & $\begin{array}{l}\text { hos2:: ura4+ ura4-D18 leu-32 ade6-216 } \\
\text { his3-D1 (base strain) }\end{array}$ & This Study \\
\hline $\mathrm{JK} 744$ & $\begin{array}{l}\text { hos2::hos } 2^{\text {Sp }} \text { ura4-D18 leu-32 ade6-216 } \\
\text { his3-D1 }\end{array}$ & This Study \\
\hline$J K 745$ & $\begin{array}{l}\text { hos2::HDAC3 }{ }^{\text {Hs }} \text { ura4-D18 leu-32 ade6-21 } \\
\text { 6his3-D1 }\end{array}$ & This Study \\
\hline JK759 & hos2::kanMX4 clp1::ura4 $4^{+}$ura4-D18 & This Study \\
\hline JK761 & hos2::kanMX4 cdc15-140 ade6-21x leu1-32 & JK Collection \\
\hline JK776 & cdc7GFP::.ura4 $4^{+}$hos2::Ura4 $4^{+}$ura4-D18 & This Study \\
\hline JK778 & clp1GFP::kanMX4 hos2::ura4+ ura4-D18 & This Study \\
\hline MBY154 & cdc15-140 ade6-21x leu1-32 h & JK Collection \\
\hline MBY624 & rlc1GFP::.ura4 $4^{+}$ura4-D18 $^{+}$ & JK Collection \\
\hline MBY978 & $\begin{array}{l}\text { clp1GFP:.:kanMX4 ura4-D18 leu1-32 } \\
\text { ade6-216 h+ }\end{array}$ & JK Collection \\
\hline MBY2415 & $\begin{array}{l}\text { cdc7GFP:.:ura4 }{ }^{+} \text {ura4-D18 ade6-21x leu1-32 } \\
\text { ura4-D18 his3-D1 h+ }\end{array}$ & JK Collection \\
\hline SCG5 & $\begin{array}{l}\text { hos2-myc:: ura4 } 4^{+} \text {ura4-D18 leu1-32 ade6-210 } \\
\text { his-D1 }\end{array}$ & This Study \\
\hline SCG10 & set3-HA::ura4 $4^{+}$hos2-myc::ura4 $4^{+}$ura4-D18 & This Study \\
\hline SCG11 & snt1-HA::ura4 ${ }^{+}$hos2-myc::ura4 $4^{+}$ura4-D18 & This Study \\
\hline SCG14 & hif2-HA::ura4 $4^{+}$hos2-myc::ura4 $4^{+}$ura4-D18 & This Study \\
\hline
\end{tabular}

reading frame in fission yeast with the human $H D A C 3$ gene (Additional File 9) [32]. This approach first required the creation of a "base strain" in which the hos 2 gene was replaced with a deletion cassette composed of the $\mathrm{ura}^{+}$selectable marker flanked by the Cre recombinase recognitions sites, loxP and loxM3. As expected, the hos $2 \Delta$ "base strain" created in this manner was indistinguishable from the Bioneer gene deletion mutant in terms of its sensitivity to LatA and its ability to complete cytokinesis in liquid LatA media (Figure 5A-C).

Next, we cloned the HDAC3 cDNA from the pOTB7 plasmid (purchased from Open Biosystems) into the XhoI and SacI sites of the "exchange" plasmid pAW8X. The exchange plasmid contains the Cre recombinase gene under control of the $n m t 41$ promoter. Once transformed into the base strain, expression of the recombinase permits exchange of the $\mathrm{ura4}^{+}$cassette with the HDAC3 sequence (Additional File 9). In this way the hos2::HDAC3 ${ }^{H s}$ (Hs, Homo sapiens) strain - in which the human HDAC3 gene is under control of the S. pombe hos 2 promoter - was created. In addition a control strain, in which the $S$. pombe hos 2 gene was re-engineered back into the base strain, hos2::hos $2^{S p}$ (Sp, Schizosaccharomyces pombe) was used as a control.

Remarkably, expression of human $H D A C 3$ in S. pombe was able to both restore viability and substantially complement the cytokinesis phenotypes characteristic of the base strain, albeit not to the same extent as the re-introduced hos2 gene (Figure 5A-C). While the base strain displayed over $50 \%$ tetra-nucleate cells after 5 hours, the hos $2:: h o s 2^{S p}$ strain displayed only $5 \%$ tetra-nucleate cells and the hos2::HDAC3 ${ }^{H s}$ strain only $18 \%$ tetra-nucleate cells. Thus, expression of the human $H D A C 3$ is indeed capable of at least partially complementing the loss of the $S$. pombe hos 2 gene.

Lastly, to provide further evidence of conserved function, we proceeded to over- express human HDAC3 under the control of the nmt1 promoter using the pREP1 plasmid. Similar to the over-expression of hos2, over-expression of HDAC3 resulted in a decrease in growth rate in the absence of thiamine (de-repressed) and similar morphological and cytokinesis phenotypes (compare Figure 3B,C with Figure 6B,C). Just as with the case of the hos 2 gene, over-expression of $H D A C 3$ resulted in a similar range of pleiotropic phenotypes including i) cells with a rounded, de-polarized appearance, ii) misplaced septa, iii) abnormally excessive and mislocalized septal deposition, iv) multiple septa v) highly elongated cells containing multiple aberrant deposits of septal material and vi) elongated and branched cells (Figure 6B,C; Table 2). Taking all data together, these results suggest that Hos2p and human HDAC3 function in a similar manner and modulate similar biological processes in S. pombe.

\section{Discussion}

While the absence of cytokinesis is tolerated under certain specialized circumstances (e.g. the development of Drosophila embryos) it is normally essential for cellular proliferation, differentiation and for maintaining control over ploidy $[1,2,33]$. Thus, knowledge of the regulatory networks governing cytokinesis is an important component of our basic understanding of eukaryotic cell biology. Moreover, aspects of this knowledge related to cytokinesis failure may also be relevant to our understanding of the mechanisms important for maintaining genomic integrity.

A relationship between cytokinesis failure and genome integrity (and thus tumourigenesis) was first proposed by Theodor Boveri in 1914 [34]. In his classic manuscript "Concerning the origin of malignant tumours" Boveri hypothesized that tetraploid intermediates derived from cytokinetic failure might undergo chaotic multipolar mitoses leading to numerical and/or structural chromosomal defects. Recent experimental evidence (reviewed in $[33,35,36]$ ) provides strong support 


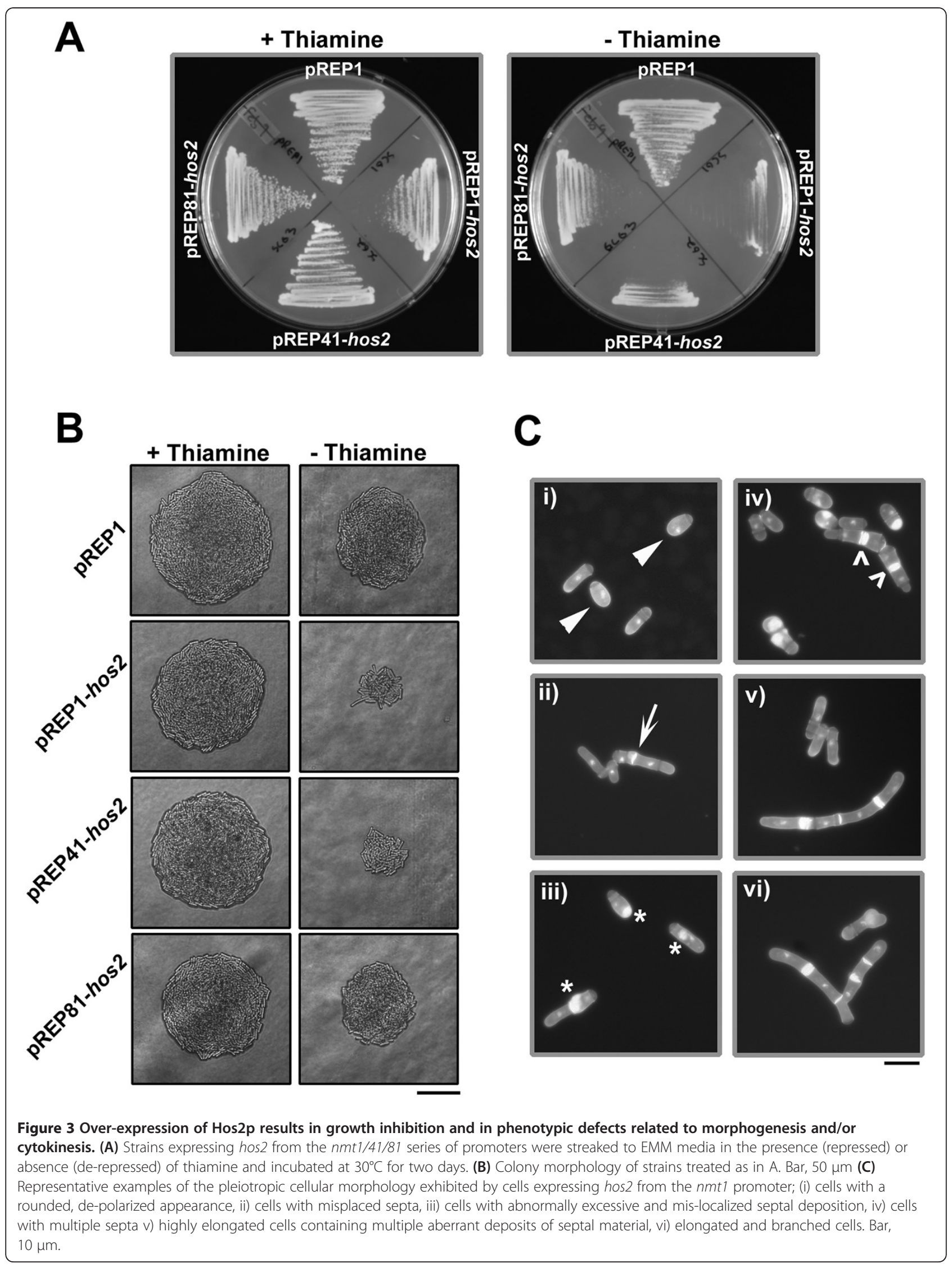


Table 2 Quantitation of phenotypic abnormalities upon hos 2 or HDAC3 over-expression from the nmt 1 promoter in the absence of thiamine

\begin{tabular}{llll}
\hline Morphological Abnormality & pREP1 & pREP1-hos2 & pREP1-HDAC3 \\
\hline Normal & $>99 \%$ & $52 \%$ & $54 \%$ \\
Rounded/Depolarized & $<1 \%$ & $26.5 \%$ & $29 \%$ \\
Misplaced septa & $<1 \%$ & $9 \%$ & $5 \%$ \\
$\begin{array}{l}\text { Excessive/Misplaced septal } \\
\text { deposits }\end{array}$ & 0 & $6 \%$ & $6 \%$ \\
$\begin{array}{l}\text { Multiple septa } \\
\begin{array}{l}\text { Elongated with multiple aberrant } \\
\text { deposits of septal material }\end{array}\end{array}$ & 0 & $3 \%$ & $2 \%$ \\
$\begin{array}{l}\text { Elongated and Branched } \\
\text { long }\end{array}$ & 0 & $1.5 \%$ & $1.5 \%$ \\
\hline
\end{tabular}

for Boveri's assertions; most notably the observation that tetraploid mouse mammary epithelial cells (generated by the inhibition of cytokinesis) display increased rates of aneuploidy and give rise to malignant tumours when transplanted into nude mice [37].

Interestingly, a recent genome-wide RNAi screen, aimed at discovering gene-products important for the fidelity of cell division in HeLa cells, identified physical interactors of HDAC3 as being important for cytokinesis [20]. In this work Kittler et al., showed that knockdown of $M L L 5$, NCOR2, or TBL1X (genes encoding putative chromatinbinding proteins implicated in transcriptional regulation) resulted in increased rates of cytokinesis failure and the generation of tetraploid intermediates [20]. Remarkably, these genes are orthologous to three fission yeast genes (set3, snt1, and hif2) recently identified as playing a role in the reliable execution of cytokinesis and which physically interact with the $S$. pombe HDAC3 ortholog, Hosp2p (Figure 4B). These results not only further validate the use of $S$. pombe as a eukaryotic model, but also raise the intriguing question of whether these orthologous complexes represent an evolutionarily conserved module important for the faithful execution of cell division.

In this report we identify the fission yeast ortholog of HDAC3 and provide further evidence of cross-species conservation. First, the expression of human HDAC3 clearly complements the cytokinesis defects displayed by hos $2 \Delta$ mutants (Figure 5). Second, over- expression of Hos2p or HDAC3 both result in phenotypes related to
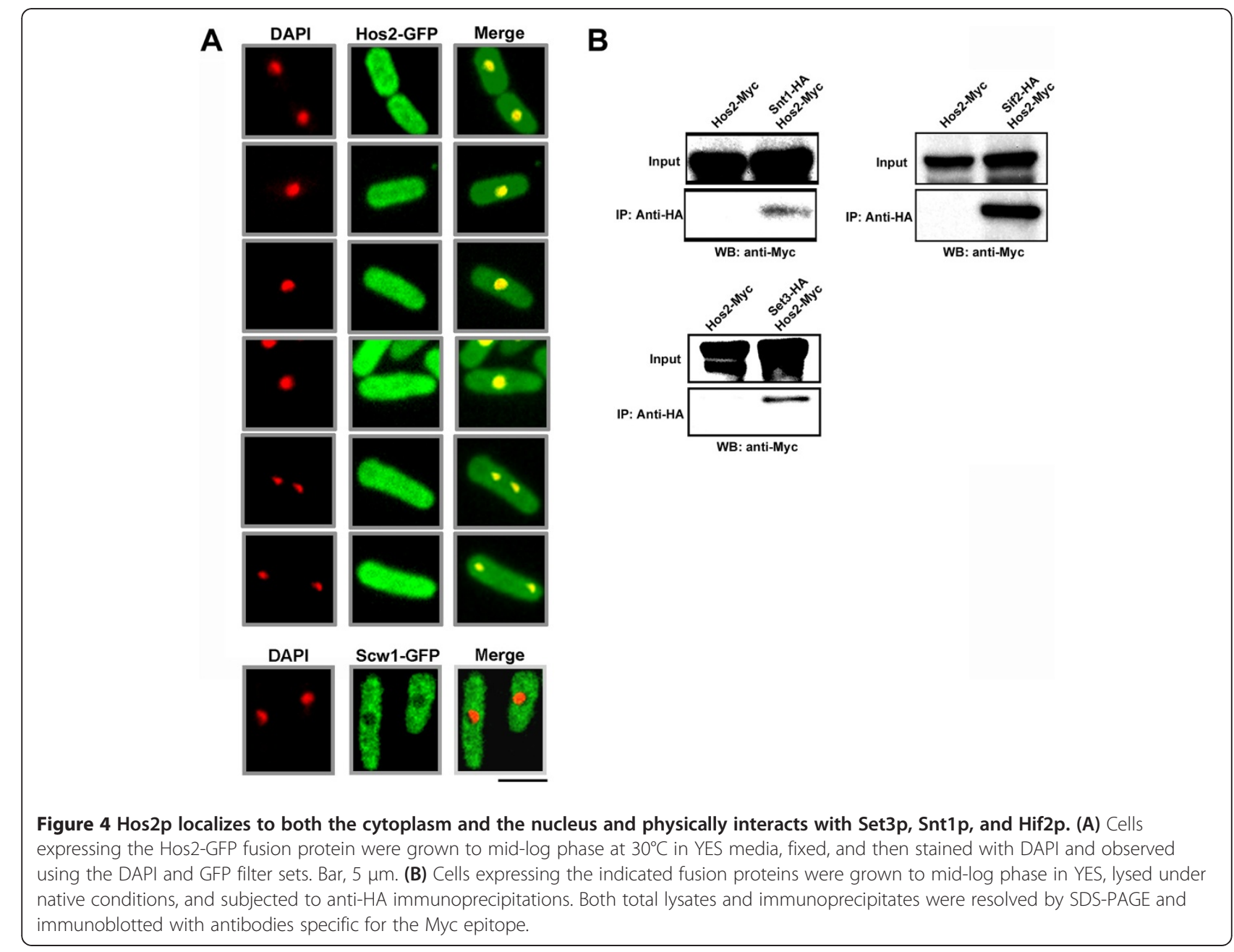


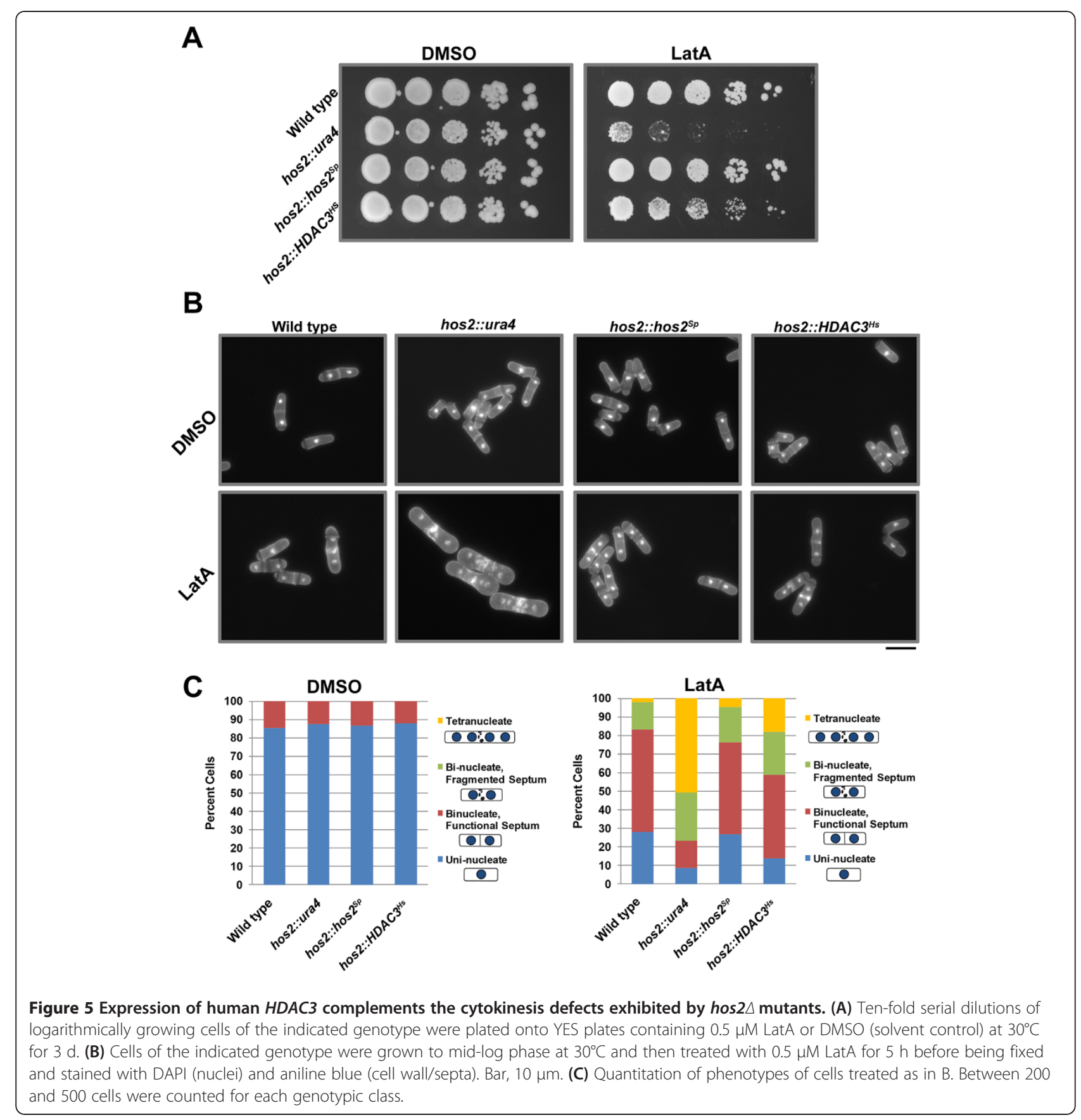

morphogenesis and/or cytokinesis (Figure 6). With respect to functional conservation, it is also important to note the similarity in localization between Hos $2 p$ and HDAC3. HDAC3 is the only member of the class I HDACs to localize to the cytoplasm, as well as the nucleus, owing to the presence of both nuclear import and export signals [38]. Thus, our observation that Hos2p localizes to both of these intracellular compartments represents another level at which Hos2p and HDAC3 share similarities (Figure 4A). Furthermore, the cytoplasmic localization observed for Hos $2 p$ is consistent with immunofluorescence data demonstrating that HA epitope tagged Hos $2 p$ is predominantly cytoplasmic as well as with global GFP-fusion based localisation studies showing both nuclear and cytoplasmic localization $[39,40]$.

We also provide genetic evidence supporting a catalytic role for Hos $2 p$ through the analysis of strains bearing the $\mathrm{Y} 321 \mathrm{H}$ mutation. The mutated tyrosine residue catalyzes stabilization of the transition state between acetyl-lysine and lysine thereby allowing for catalysis of lysine deacetylation; this is not chemically possible through a histidine residue [41]. As expected if Hos2p 
A

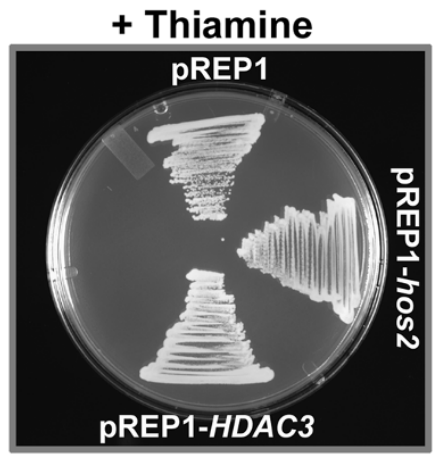

B

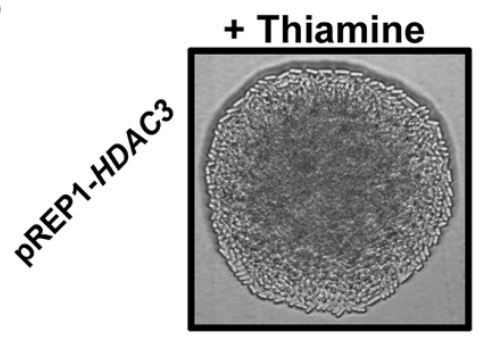

C
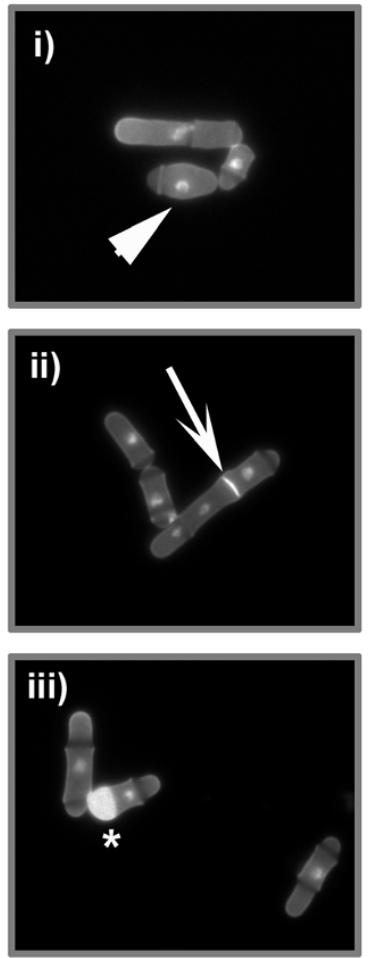

\section{- Thiamine}

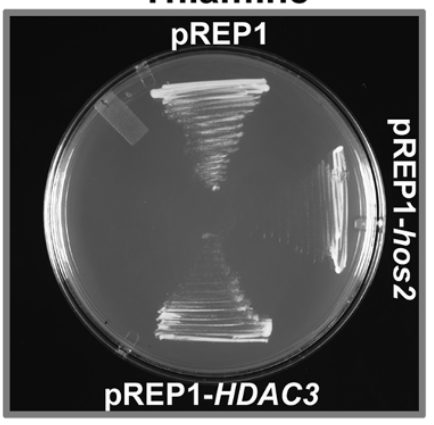

- Thiamine
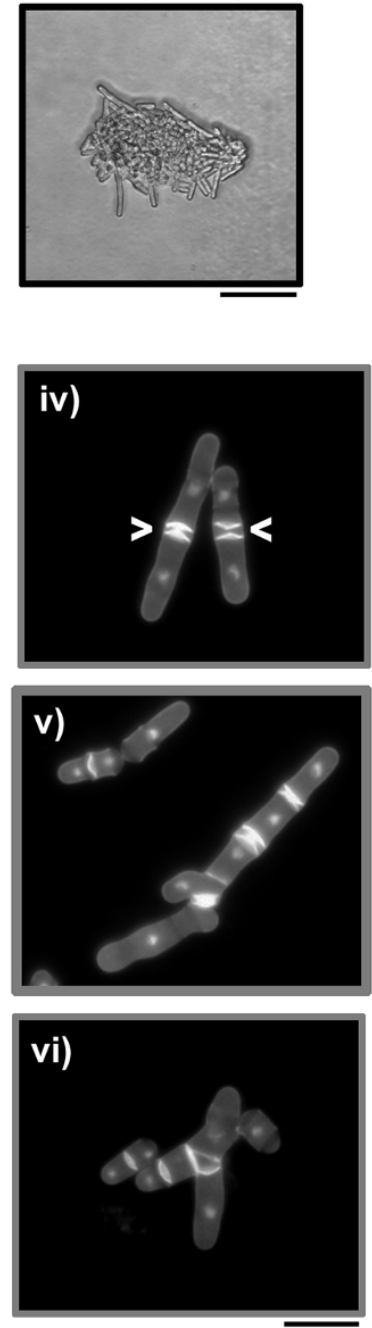

Figure 6 Similarly to the over-expression of Hos2p, over-expression of human HDAC3 results in growth inhibition and in phenotypic defects related to morphogenesis and/or cytokinesis. (A) Strains expressing hos 2 or HDAC3 from the nmt1 promoter were streaked to EMM media in the presence (repressed) or absence (de-repressed) of thiamine and incubated at $30^{\circ} \mathrm{C}$ for two days. (B) Colony morphology of strains treated as in A. Bar, 50 m (C). Representative examples of the pleiotropic cellular morphology exhibited by cells expressing HDAC3 from the nmt1 promoter; (i) cells with a rounded, de-polarized appearance, ii) cells with misplaced septa, iii) cells with abnormally excessive and mislocalized septal deposition, iv) cells with multiple septa v) highly elongated cells containing multiple aberrant deposits of septal material, vi) elongated and branched cells. Bar, $10 \mu \mathrm{m}$. 
played a catalytic role, hos $2-Y 321 H$ mutants displayed phenotypes similar to those exhibited by hos $2 \Delta$ strains. In fact, the severity of the cytokinesis defects was greater in the site-mutant compared to the gene deletion (Figure 1). We speculate that the increase in severity of the phenotype may be related to the presence of the mutant protein interfering with other components of the pathway in a dominant negative fashion.

While targeted deacetylation is likely an important aspect of Hos $2 p$ function, the physiological substrates of the Hos2p-Set3p-Snt1p-Hif2p complex remain unknown. One possibility is that cytokinetic failure is related to transcriptional defects stemming from the abnormal acetylation of histones. A role in transcription is supported by the observation that set $3 \Delta$ mutants are compromised in their ability to alter the expression of stress response genes upon LatA treatment. Thus, cell division failure may be a manifestation of the inability of the mutants to properly counter the effects of LatA induced stress leading to the direct and/or indirect effects on the function of the cytokinetic machinery. When considering such models it should also be noted that the substrate specificity of HDACs is not restricted to histones. In fact, many non-histone substrates, including transcription factors, signalling molecules, and nuclear import factors have been identified as targets [42]. Thus, the possibility exists that the complex may function through both the modulation of transcription and/ or the post modification of non-histone targets.

Finally, while highly speculative, it is interesting to note that the liver specific deletion of HDAC3 results in hepatocellular carcinoma in mice [43]. In this work, 20 out of 20 $H D A C 3^{-/-}$displayed low grade hepatocellular carcinoma at a mean age of 10.2 months. Although a role for cytokinesis failure in this phenotype has not been examined, it is interesting to speculate as to whether it played any role in tumour development in this context. Regardless, the demonstration of functional conservation between HDAC3 and Hos2p suggests that further analysis of these proteins in fission yeast might translate into a theoretical framework for understanding the role of HDAC3 in both the regulation of cytokinesis as well as other biological processes influenced by HDAC3 deacetylation.

\section{Conclusions}

In this work we demonstrate a role for the histone deacetylase, Hos $2 p$, in promoting the faithful and dependable execution of cytokinesis in fission yeast. Analysis of catalytically inactive hos $2-Y 321 H$ mutants suggests that its role in this process is mediated through its deacetylase activity. In addition, co-immunoprecipitation experiments indicate that Hos $2 p$ regulates cytokinesis as part of a complex with Set3p, Snt1p, and Hif2p (all of which play a documented role in preventing cell division failure). Lastly, the ability of human HDAC3 to complement the cytokinesis defects exhibited by hos $2 \Delta$ mutants suggests that continued analysis of this system could translate into a theoretical framework for understanding how HDAC3 functions in more developmentally complex organisms.

\section{Methods \\ Yeast methods}

All Schizosaccharomyces pombe strains used in this study are listed in Table 1. Strains were derived from the Karagiannis lab collection, constructed during the course of this work, or purchased from Bioneer Corporation (Alameda, CA). S. pombe cells were cultured in YES or in Edinburgh Minimal Media (EMM) supplemented with adenine, histidine, leucine, and/or uracil. Liquid cultures were grown with shaking $(200 \mathrm{rpm})$ at $30^{\circ} \mathrm{C}$ [44]. In experiments involving Latrunculin treatment, $S$. pombe cells were grown to mid log phase (O.D. 0.2) and treated with 0.1-0.5 $\mu \mathrm{M}$ of Latrunculin A (Enzo Life Sciences International, Plymouth Meeting, Pennsylvania) dissolved in DMSO. Cells were grown at $30^{\circ} \mathrm{C}$ with shaking at $200 \mathrm{rpm}$ for 3-6 hrs, before being fixed with ethanol and stored in PBS pH 7.4. All experiments were repeated a minimum of three times. Plasmid vectors were transformed into $S$. pombe using the lithium acetate protocol according to Forsburg and Rhind [44].

\section{Fluorescence microscopy}

To observe nuclei and cell wall/septa material, cells were prepared as described above (see Yeast Methods) and mixed with $0.02 \mu \mathrm{g} / \mu \mathrm{L}$ 4'6,-diamidino-2-phenylindole (DAPI) and $1 \mu \mathrm{g} / \mu \mathrm{L}$ aniline blue. In colocalization experiments, S. pombe cells expressing the Hos2-GFP fusion were fixed with ethanol and stored in PBS pH 7.4 To observe nuclei and cell wall/septa material, cells were mixed with DAPI and $1 \mu \mathrm{g} / \mu \mathrm{L}$ aniline blue prior to observation with the DAPI and GFP filter sets. In timelapse experiments log-phase cells expressing the Rlc1GFP fusion were imaged live using the CellAsics ONIX ${ }^{\mathrm{m}}$ Microfluidic Perfusion Platform while perfusing liquid YES growth medium containing $0.5 \mu \mathrm{M}$ LatA or DMSO as a solvent control. All Images were acquired using a Leica DMI6000B inverted microscope equipped with a 100X Plan Apochromat 1.4 NA Oil objective, a Photometrics QuantEM:512SC EMCCD camera, in conjunction with a BDCARVII spinning disk confocal imager (Z-resolution of $0.5 \mu \mathrm{m}$ ) driven by Metamorph software.

\section{Cloning methods}

S. pombe strains expressing carboxy-terminal epitope tagged fusion proteins were constructed using a PCR based cloning strategy. To create the Hos2-GFP and Hos2-Myc expressing strains a C-terminal fragment of the hos 2 gene was PCR amplified using High- Fidelity PCR Enzyme Mix (Fermentas Life Sciences) from $S$. 
pombe genomic DNA with the forward primer 5'-GGG GGG AAT TCT GAA CGA ATT TTT CGC ACC AGA T-3' and reverse primer $5^{\prime}$-GGG GGC CCG GGG CCT CGA ACG CGA ACA TC-3' and cloned in frame into the EcoRI and SmaI sites of the pJK210-GFP and pJK210-Myc vectors respectively. Molecular cloning of the desired C-terminal fragments was confirmed by restriction digestion and DNA sequencing. Plasmid clones containing the desired C-terminal fragment were transformed into S. pombe strain MBY1343 (ura4-D18). Ura ${ }^{+}$ integrants were selected for by growth on EMM lacking uracil and subjected to colony PCR to identify clones in which the construct had integrated into the genome via homologous recombination. HA epitope-tagged versions of Set3p, Hif2p, and Snt1p were created as described earlier.

Thiamine repressible hos 2 expression plasmids were created by PCR amplifying the hos 2 gene (forward primer: 5'-GGG GGA TTA ATA TGG ATA CTC CTG AGA CAT CCA CAC-3'; reverse primer: 5'-GGG GGG GAT CCT CAG CCT CGA ACG CGA AC-3') from wild-type genomic DNA and cloning into the NdeI and BamHI sites of pREP1/41/81. Plasmids were then transformed into strain JK484 (Table 1) using the LiAc method and Leu + transformants selected in EMM media supplemented with adenine, uracil, and histidine.

Plasmid bearing strains were grown in supplemented $\mathrm{EMM}+$ thiamine overnight, washed three times with EMM media, and then cultured for $24 \mathrm{hrs}$. Cells were then fixed with ethanol, stained with DAPI and analine blue, and imaged using a Leica DMI6000B microscope driven by Metamorph software using the DAPI filter set.

To determine the effects of HDAC3 over-expression, the full length human $H D A C 3 \mathrm{cDNA}$, was PCR amplified (forward primer: 5'-GAT CGA TTA ATA TGG CCA AGA CCG TGG CC-3'; reverse primer: 5'-CGA TCG GAT CCT TAA ATC TCC ACA TCG CTT T-3') from the pOTB7 plasmid (Open Biosystems) and cloned into the NdeI and BamHI sites of the pREP series of plasmids. The plasmids were then transformed into JK484 (Table 1) and the effects of over-expression examined as described above.

To create the hos $2-Y 321 H$ mutant, an N-terminal fragment of the hos 2 gene was PCR amplified with a reverse primer incorporating the $\mathrm{Y} 321 \mathrm{H}$ mutation (forward primer \#1: 5'- GGG GGG AAT TCT GAC GTG GTG AGG CTA GTG GAT TC-3'; reverse primer \#1: $5^{\prime}$ TTT CTA AGA GTA TGA CCA CCA CCT C-3'). Similarly, a C-terminal fragment of the hos 2 gene was PCR amplified with a forward primer incorporating the Y321H mutation (forward primer \#2: 5'-GAG GTG GTG GTC ATA CTC TTA GAA A-3'; reverse primer \#2: 5'-GGG GGC CCG GGG CCT CGA ACG CGA ACA TC-3'). A full-length product containing the desired mutations was then PCR amplified using forward primer \#1, reverse primer \#2, and the products of the first two reactions as template. The full-length product was then cloned into the EcoRI and SmaI sites of the pJK210 vector and the construct transformed into JK484 (Table 1) to obtain integrants. Ura + transformants were then isolated and subjected to colony PCR to identify clones in which the construct had integrated into the genome via homologous integration.

\section{Biochemical and immunological methods}

Cells of the indicated genotype were grown to the mid$\log$ phase at $30^{\circ} \mathrm{C}$, collected by centrifugation, and resuspended in STOP buffer $(10 \mathrm{mM}$ Tris- $\mathrm{HCl} \mathrm{pH}$ 8.0, $150 \mathrm{mM} \mathrm{NaCl}, 50 \mathrm{mM} \mathrm{NaF}, 10 \mathrm{mM}$ EDTA, $1 \mathrm{mM}$ $\mathrm{NaN}_{3}$ ). Cell pellets were stored at $-80^{\circ} \mathrm{C}$ up to a maximum of 6 months. Cell pellets were subsequently thawed, and lysed using vortexing with glass beads in extraction buffer (1\% IGEPAL CA630 (tetr-Octylphenoxy polyethanol), $150 \mathrm{mM} \mathrm{NaCl}, 50 \mathrm{mM}$ Tris- $\mathrm{HCl} \mathrm{pH} 8.0$, 2 mM EDTA, $1 \mathrm{mM}$ PMSF (phenylmethanesulphonylfluoride), $2 \mathrm{mM}$ Benzamidine, $50 \mathrm{mM} \mathrm{NaF}, 0.1 \mathrm{mM}$ $\mathrm{Na}_{3} \mathrm{VO}_{4}, 50 \mathrm{mM}$ B-glycerophosphate, $15 \mathrm{mM}$ p-nitrophenyl phosphate, $1 / 4$ Tablet Sigma Protease Inhibitors). Immunoprecipitations were performed using Protein G Dynabeads $^{\circ}$ (Invitrogen) according to the manufacturer's protocol. Briefly, anti-HA antibodies (HA.11; Sigma) were incubated with Protein G Dynabeads in extraction buffer. Cell extracts were then added to the antibodybound bead slurry. After incubation and repeated washing with extraction buffer, the bound proteins were eluted by incubation at $96^{\circ} \mathrm{C}$ for 5 minutes. The eluted proteins were then subjected to SDS-PAGE, transferred to PVDF membranes and probed with anti-Myc antibodies (9E10; Sigma).

\section{Recombinase mediated cassette exchange}

The hos 2 "base" strain was created by deleting the hos 2 coding sequence with the loxP-ura $4^{+}$-loxM3 deletion cassette amplified from the pAW1 plasmid (forward primer: 5'- GTT TCT TAA TTT TAT TTA TTC TTT TCT TGT TCT TTC TTT AGA AAA GAT ATT TTC ATT TAA TTT GTC TCG CGG TTT TTT TTA GTA TAA TAG TCT GTA TAT CCG GAT CCC CGG GTT AAT TAA-3'; reverse primer: 5' - TAT AGG GTC AAT TAT TAA TAT TTA CAA TGT CTA TAA ACA TTA ACT AAA ATT ATT TGA TGT TTG TAC GGA TAT CAA ATA AAA AGT CGA AAA TTC ATT AAT AGA ATT CGA GCT CGT TTA AAC-3'). Deletion cassettes were transformed into JK484 using the lithium acetate method to obtain integrants. Ura + transformants were then isolated and subjected to colony PCR to identify clones in which the construct had integrated into the genome via homologous integration. 
The hos2 "exchange" cassette was constructed by PCR amplifying the hos2 gene from the pREP1-hos2 plasmid (forward primer: 5'-GGC GGC TCG AGA TGG ATA CTC CTG AGA CAT CCA CAC-3'; reverse primer; 5' GGC GGG AGC TCT CAG CCT CGA ACG CGA AC$\left.3^{\prime}\right)$. The amplicon was then cloned into the Xho1 and SacI sites of the pAW8X plasmid. The HDAC3 exchange cassette was constructed by PCR amplifying the HDAC3 cDNA gene from the pOTB7 plasmid (Open Biosystems) (forward primer: 5' - GGC GG C TCG AGA TGG CCA AGA CCG TGG C-3'; reverse primer: 5'-GGC GGG AGC TC T TAA ATC TCC ACA TCG CTT TCC TT$\left.3^{\prime}\right)$. The amplicon was then cloned into the XhoI and SacI sites of the pAW8X plasmid. Exchange of the $\mathrm{ura4}^{+}$ gene with either hos 2 or $H D A C 3$ was achieved according to the protocol of Watson et al. [32].

\section{Additional files}

Additional file 1: Hos $2 p$ shares significant sequence similarity to human HDAC3. (A) Phylogenetic relationship of Hos $2 p$ orthologs from yeast to humans. (B) Domain structure of fission yeast Hos $2 \mathrm{p}$, and human HDAC3. Red diamond indicates conserved Y321 residue necessary for catalysis. (C) ClustalW alignment of fission yeast Hos2p, and human HDAC3. Stars indicate amino acid identity and "." indicates amino acid similarity. Red arrow indicates conserved Y321 residue necessary for catalysis.

Additional file 2: Clp1p and Cdc7p localization upon LatA treatment in hos $2 \triangle$ backgrounds. (A) Wild-type and hos $2 \Delta$ strains expressing Clp1-GFP were grown to mid-log phase at $30^{\circ} \mathrm{C}$ and then treated with $0.5 \mu \mathrm{M}$ LatA for $3 \mathrm{~h}$ before fluorescence imaging. Asterisks indicate cells in which Clp $1 \mathrm{p}$ is enriched in the cytoplasm indicating active SIN signaling. Bar, $10 \mu \mathrm{m}$. (B) Wild-type and hos $2 \Delta$ strains expressing Cdc7-GFP were grown to mid-log phase at $30^{\circ} \mathrm{C}$ and then treated with $0.5 \mu \mathrm{M}$ LatA for $3 \mathrm{~h}$ before fluorescence imaging. Arrows indicate cells in which Cdc7p localizes asymmetrically to one of two available SPBs indicating active SIN signaling. Bar, $10 \mu \mathrm{m}$.

Additional file 3: $c / p 1 \triangle$ hos $2 \triangle$ double mutants display increased sensitivity to LatA relative to both $\operatorname{clp} 1 \triangle$ and hos $2 \Delta$ single mutants. Cells of the indicated genotype were grown to mid-log phase at $30^{\circ} \mathrm{C}$ and then treated with 0.1 or $0.5 \mu \mathrm{M}$ LatA for $5 \mathrm{~h}$ before being fixed and stained with DAPI (nuclei) and aniline blue (cell wall/septa). Bar, $10 \mu \mathrm{m}$.

Additional file 4: the hos 2 gene deletion reduces the restrictive temperature of the cdc15-140 mutation. Cells of the indicated genotype were streaked to YES plates and incubated over-night At $25^{\circ} \mathrm{C}$, $31^{\circ} \mathrm{C}$, or $36^{\circ} \mathrm{C}$. Bar, $50 \mu \mathrm{m}$

Additional file 5: Time-lapse movie of Rlc1-GFP dynamics in wildtype cells treated with DMSO.

Additional file 6: Time-lapse movie of Rlc1-GFP dynamics in hos2 $\triangle$ cells treated with DMSO.

Additional file 7: Time-lapse movie of Rlc1-GFP dynamics in wildtype cells treated with $0.5 \mu \mathrm{M}$ LatA.

Additional file 8: Time-lapse movie of RIc1-GFP dynamics in hos $2 \triangle$ cells treated with $0.5 \mu \mathrm{M}$ LatA.

Additional file 9: Schematic representation of recombinasemediated cassette exchange. A "base-strain" is first created in which the hos 2 open reading frame is replaced with a deletion cassette composed of the $\mathrm{ura}^{+}$selectable marker flanked by the Cre recombinase recognitions sites, loxP and loxM3. Next, the "exchange" plasmid (pAW8X-HDAC3) containing the Cre recombinase gene under control of the nmt41 promoter is transformed into the base strain.
Expression of the recombinase permits exchange of the $\mathrm{urat}^{+}$cassette with the HDAC3 sequence.

\section{Abbreviations}

HDAC: Histone Deacetylase; SIN: Septation Initiation Network; YES: Yeast Extract Supplements; EMM: Edinburgh Minimal Media; LatA: Latrunculin A; DMSO: Dimethyl sulfoxide; DAPI: 4',6-diamidino-2-phenylindole;

PBS: Phosphate Buffered Saline.

\section{Competing interests}

The authors declare that they have no competing interests.

\section{Authors' contributions}

JK designed the experiments and drafted the manuscript. CG, JH, SR, and JK performed the experiments and analysed the data. All authors read and approved the final manuscript.

\section{Authors' information}

At the time of their contributions CG and SR were MSc candidates at the UWO Department of Biology. CG is currently a PhD candidate at the University of Alberta. SR is currently a PhD candidate at McGill University. JH is a BSC (Hons) student at the UWO Department of Biology. JK is an Assistant Professor at the UWO Department of Biology.

\section{Acknowledgements}

This work was supported by the National Sciences and Engineering Research Council of Canada, the University of Western Ontario Academic Development Fund, and the Canada Foundation for Innovation. We would also like to thank members of the UWO Biology and Biochemistry Departments for helpful discussions and/or critical reading of the manuscript.

Received: 22 December 2011 Accepted: 20 April 2012

Published: 4 May 2012

\section{References}

1. Guertin DA, Trautmann S, McCollum D: Cytokinesis in eukaryotes. Microbiol Mol Biol Rev 2002, 66:155-178.

2. Balasubramanian MK, Bi E, Glotzer M: Comparative analysis of cytokinesis in budding yeast, fission yeast and animal cells. Curr Biol 2004, 14: R806-R818.

3. Krapp A, Simanis $V$ : An overview of the fission yeast septation initiation network (SIN). Biochem Soc Trans 2008, 36:411-415.

4. Pollard TD: Mechanics of cytokinesis in eukaryotes. Curr Opin Cell Biol 2010, 22:50-56.

5. Bathe $\mathrm{M}$, Chang $\mathrm{F}$ : Cytokinesis and the contractile ring in fission yeast: towards a systems-level understanding. Trends Microbiol 2010, 18:38-45.

6. McCollum D: Cytokinesis: ER keeps Mid1 in the middle. Curr Biol 2010, 20: R484-R486.

7. Almonacid M, Paoletti A: Mechanisms controlling division-plane positioning. Semin Cell Dev Biol 2010, 21:874-880.

8. Almonacid M, Moseley JB, Janvore J, Mayeux A, Fraisier V, Nurse P, Paoletti A: Spatial control of cytokinesis by $\mathrm{Cdr} 2$ kinase and Mid1/anillin nuclear export. Curr Biol 2009, 19:961-966.

9. Hachet $\mathrm{O}$, Simanis V: Mid1p/anillin and the septation initiation network orchestrate contractile ring assembly for cytokinesis. Genes Dev 2008, 22:3205-3216

10. Krapp A, Gulli MP, Simanis V: SIN and the art of splitting the fission yeast cell. Curr Biol 2004, 14:R722-R730.

11. Saberianfar R, Cunningham-Dunlop S, Karagiannis J: Global gene expression analysis of fission yeast mutants impaired in Ser-2 phosphorylation of the RNA pol II carboxy terminal domain. PLoS One 2011, 6:e24694.

12. Karagiannis J, Balasubramanian MK: A cyclin-dependent kinase that promotes cytokinesis through modulating phosphorylation of the carboxy terminal domain of the RNA Pol II Rpb1p sub-unit. PLoS One 2007, 2:e433.

13. Mishra M, Karagiannis J, Sevugan M, Singh P, Balasubramanian MK: The 143-3 protein rad24p modulates function of the cdc14p family phosphatase clp1p/flp1p in fission yeast. Curr Biol 2005, 15:1376-1383. 
14. Karagiannis J, Bimbo A, Rajagopalan S, Liu J, Balasubramanian MK: The nuclear kinase Lsk1p positively regulates the septation initiation network and promotes the successful completion of cytokinesis in response to perturbation of the actomyosin ring in Schizosaccharomyces pombe. Mol Biol Cell 2005, 16:358-371.

15. Mishra M, Karagiannis J, Trautmann S, Wang H, McCollum D, Balasubramanian MK: The Clp1p/Flp1p phosphatase ensures completion of cytokinesis in response to minor perturbation of the cell division machinery in Schizosaccharomyces pombe. J Cell Sci 2004, 117:3897-3910.

16. Liu J, Wang H, Balasubramanian MK: A checkpoint that monitors cytokinesis in Schizosaccharomyces pombe. J Cell Sci 2000, 113(Pt 7):1223-1230

17. Le Goff X, Woollard A, Simanis V: Analysis of the cps1 gene provides evidence for a septation checkpoint in Schizosaccharomyces pombe. Mol Gen Genet 1999, 262:163-172.

18. Chen CT, Feoktistova A, Chen JS, Shim YS, Clifford DM, Gould KL, McCollum $D$ : The SIN kinase Sid2 regulates cytoplasmic retention of the $S$. pombe Cdc14-like phosphatase Clp1. Curr Biol 2008, 18:1594-1599.

19. Rentas S, Saberianfar R, Grewal C, Kanippayoor R, Mishra M, McCollum D, Karagiannis J: The SET domain protein, Set3p, promotes the reliable execution of cytokinesis in Schizosaccharomyces pombe. PLoS One 2012, 7:e31224.

20. Kittler R, Pelletier L, Heninger AK, Slabicki M, Theis M, Miroslaw L, Poser I, Lawo S, Grabner H, Kozak K, et al: Genome-scale RNAi profiling of cell division in human tissue culture cells. Nat Cell Biol 2007, 9:1401-1412.

21. Yoon HG, Chan DW, Huang ZQ, Li J, Fondell JD, Qin J, Wong J: Purification and functional characterization of the human N-CoR complex: the roles of HDAC3, TBL1 and TBLR1. EMBO J 2003, 22:1336-1346.

22. Zhang J, Kalkum M, Chait BT, Roeder RG: The N-CoR-HDAC3 nuclear receptor corepressor complex inhibits the JNK pathway through the integral subunit GPS2. Mol Cell 2002, 9:611-623.

23. Olsson TG, Ekwall K, Allshire RC, Sunnerhagen P, Partridge JF, Richardson WA: Genetic characterisation of hda1+, a putative fission yeast histone deacetylase gene. Nucleic Acids Res 1998, 26:3247-3254.

24. Sinha I, Wiren M, Ekwall K: Genome-wide patterns of histone modifications in fission yeast. Chromosome Res 2006, 14:95-105.

25. Wiren M, Silverstein RA, Sinha I, Walfridsson J, Lee HM, Laurenson P, Pillus L, Robyr D, Grunstein M, Ekwall K: Genomewide analysis of nucleosome density histone acetylation and HDAC function in fission yeast. EMBO J 2005, 24:2906-2918

26. Wolfe BA, Gould KL: Split decisions: coordinating cytokinesis in yeast. Trends Cell Biol 2005, 15:10-18.

27. Le Goff X, Motegi F, Salimova E, Mabuchi I, Simanis V: The S. pombe rlc1 gene encodes a putative myosin regulatory light chain that binds the type II myosins myo3p and myo2p. J Cell Sci 2000, 113(Pt 23): 4157-4163.

28. Basi G, Schmid E, Maundrell K: TATA box mutations in the Schizosaccharomyces pombe nmt1 promoter affect transcription efficiency but not the transcription start point or thiamine repressibility. Gene 1993, 123:131-136.

29. Maundrell $\mathrm{K}: \mathrm{nmt} 1$ of fission yeast. A highly transcribed gene completely repressed by thiamine. J Biol Chem 1990, 265:10857-10864.

30. Karagiannis J, Oulton R, Young PG: The Scw1 RNA-binding domain protein regulates septation and cell-wall structure in fission yeast. Genetics 2002, 162:45-58.

31. Shevchenko A, Roguev A, Schaft D, Buchanan L, Habermann B, Sakalar C, Thomas H, Krogan NJ, Stewart AF: Chromatin Central: towards the comparative proteome by accurate mapping of the yeast proteomic environment. Genome Biol 2008, 9:R167.

32. Watson AT, Garcia V, Bone N, Carr AM, Armstrong J: Gene tagging and gene replacement using recombinase-mediated cassette exchange in Schizosaccharomyces pombe. Gene 2008, 407:63-74.

33. Ganem NJ, Storchova Z, Pellman D: Tetraploidy, aneuploidy and cancer. Curr Opin Genet Dev 2007, 17:157-162.

34. Harris $\mathrm{H}$ : Concerning the origin of malignant tumours by Theodor Boveri. Translated and annotated by Henry Harris. Preface. J Cell Sci 2008, 121(Suppl1)v-vi.

35. King RW: When $2+2=5$ : the origins and fates of aneuploid and tetraploid cells. Biochim Biophys Acta 2008, 1786:4-14.

36. Sagona AP, Stenmark H: Cytokinesis and cancer. FEBS Lett 2010, 584:2652-2661.
37. Fujiwara T, Bandi M, Nitta M, Ivanova EV, Bronson RT, Pellman D: Cytokinesis failure generating tetraploids promotes tumorigenesis in p53-null cells. Nature 2005, 437:1043-1047.

38. Yang WM, Tsai SC, Wen YD, Fejer G, Seto E: Functional domains of histone deacetylase-3. J Biol Chem 2002, 277:9447-9454.

39. Bjerling P, Silverstein RA, Thon G, Caudy A, Grewal S, Ekwall K: Functional divergence between histone deacetylases in fission yeast by distinct cellular localization and in vivo specificity. Mol Cell Biol 2002, 22:21702181.

40. Matsuyama A, Arai R, Yashiroda Y, Shirai A, Kamata A, Sekido S, Kobayashi Y, Hashimoto A, Hamamoto M, Hiraoka Y, et al: ORFeome cloning and global analysis of protein localization in the fission yeast Schizosaccharomyces pombe. Nat Biotechnol 2006, 24:841-847.

41. Lahm A, Paolini C, Pallaoro M, Nardi MC, Jones P, Neddermann P, Sambucini S, Bottomley MJ, Lo Surdo P, Carfi A, et al: Unraveling the hidden catalytic activity of vertebrate class Ila histone deacetylases. Proc Natl Acad Sci U S A 2007, 104:17335-17340.

42. Karagianni P, Wong J: HDAC3: taking the SMRT-N-CoRrect road to repression. Oncogene 2007, 26:5439-5449.

43. Bhaskara S, Knutson SK, Jiang G, Chandrasekharan MB, Wilson AJ, Zheng S, Yenamandra A, Locke K, Yuan JL, Bonine-Summers AR, et al: Hdac3 is essential for the maintenance of chromatin structure and genome stability. Cancer Cell 2010, 18:436-447.

44. Forsburg SL, Rhind N: Basic methods for fission yeast. Yeast 2006, 23:173-183.

doi:10.1186/1747-1028-7-13

Cite this article as: Grewal et al: A conserved histone deacetylase with a role in the regulation of cytokinesis in Schizosaccharomyces pombe. Cell Division 2012 7:13.

\section{Submit your next manuscript to BioMed Central and take full advantage of:}

- Convenient online submission

- Thorough peer review

- No space constraints or color figure charges

- Immediate publication on acceptance

- Inclusion in PubMed, CAS, Scopus and Google Scholar

- Research which is freely available for redistribution

Submit your manuscript at www.biomedcentral.com/submit
C) Biomed Central 